\title{
Risk for contralateral breast cancer among carriers of the CHEK2*I loodelC mutation in the WECARE Study
}

\author{
L Mellemkjær*, ', C Dahl'2, JH Olsen', L Bertelsen', P Guldberg ${ }^{2}$, J Christensen', A-L Børresen-Dale ${ }^{3,4}$, \\ M Stovall ${ }^{5}$, B Langholz ${ }^{6}$, L Bernstein ${ }^{6}$, CF Lynch $^{7}$, KE Malone $^{8}$, RW Haile ${ }^{6}$, M Andersson ${ }^{9}$, DC Thomas ${ }^{6}$, \\ P Concannon ${ }^{10}$, M Capanu' ', JD Boice Jr' ${ }^{12,13}$, The WECARE Study Collaborative Group ${ }^{14}$ and JL Bernstein"
}

'Institute of Cancer Epidemiology, Danish Cancer Society, Strandboulevarden 49, DK-2 100 Copenhagen, Denmark; ${ }^{2}$ Institute of Cancer Biology, Danish Cancer Society, Strandboulevarden 49, DK-2 100 Copenhagen, Denmark; ${ }^{3}$ Department of Genetics, Institute for Cancer Research, The Norwegian Radium Hospital, N-03 10 Oslo, Nonway; ${ }^{4}$ Faculty of Medicine, University of Oslo, Postboks 1 I 7 I Blindern, N03 I 8 Oslo, Nonway; ${ }^{5}$ Department of Radiation Physics, Unit 544, The University of Texas MD Anderson Cancer Center, 1515 Holcombe, Houston, TX 77030, USA; ${ }^{6}$ Department of Preventive Medicine, University of Southern California, I44I Eastlake Avenue USC/Norris Comprehensive Cancer Center NOR-4435, Los Angeles, CA 90089-9175, USA; 7 Department of Epidemiology, University of lowa, 200 Hawkins Drive, lowa City, IA 52242, USA; ${ }^{8}$ Division of Public Health Sciences, Fred Hutchinson Cancer Research Center, 1100 Fainview Avenue North, M4-B814, Seattle, WA 98109, USA; ${ }^{2}$ Department of Oncology, The Finsen Center, Rigshospitalet, University of Copenhagen, Blegdamsvej 9, Copenhagen DK-2100, Denmark; ${ }^{10}$ Department of Biochemistry and Molecular Genetics, University of Virginia, PO Box 800733, Charlottesville, VA 22908, USA; "'Department of Epidemiology and Biostatistics, Memorial Sloan-Kettering Cancer Center, 307 East 63rd Street, 3rd Floor, New York, NY 1002 I, USA; ${ }^{12}$ International Epidemiology Institute, I 455 Research Blvd, Suite 550, Rockville, MD 20850, USA; ${ }^{13}$ Department of Medicine, Vanderbilt University Medical Center, 2 Ist Avenue South and Garland Avenue, Nashville, TN 37232, USA

The protein encoded by the CHEK2 gene is involved in cellular repair of DNA damage. The truncating mutation, CHEK2* I I 00delC, seems to increase the risk for breast cancer. We investigated whether the $\mathrm{CHEK2}$ * I I O0delC mutation carrier status increases the risk for asynchronous contralateral breast cancer (CBC) and whether it interacts with radiation therapy (RT) or chemotherapy in regard to $C B C$ risk. The germline mutation frequency was assessed in 708 women with $C B C$ and 1395 women with unilateral breast cancer $(\mathrm{UBC})$ in the Women's Environment, Cancer and Radiation Epidemiology (WECARE) Study whose first primary breast cancer was diagnosed before age 55 years and during 1985-1999. Seven women with CBC (1.0\%) and 10 women with UBC (0.7\%) were CHEK2* I l 00delC variant carriers (rate ratio $(R R)=1.8,95 \%$ confidence interval $(C I)=0.6-5.4$ for CBC vs UBC). Carriers who received $\mathrm{RT}$ for their first breast cancer, compared with non-carriers not treated with $\mathrm{RT}$, had an RR of developing CBC of 2.6 ( $95 \%$ $\mathrm{Cl}=0.8-8.7)$. We found no significant associations between the CHEK2*1 I00delC mutation and CBC overall or among those treated with RT. However, the sampling variability was such that modest increases in risk could not be excluded. Nonetheless, because this is a rare mutation, it is unlikely to explain a major fraction of $\mathrm{CBC}$ in the population.

British Journal of Cancer (2008) 98, 728-733. doi:I0.1038/sj.bjc.6604228 www.bjcancer.com

Published online 5 February 2008

(c) 2008 Cancer Research UK

Keywords: asynchronous contralateral breast cancer; CHEK2* I I00delC mutation; genes; radiation therapy; chemotherapy

The CHEK2 gene codes for a protein that is involved in cell-cycle control and DNA repair. A protein-truncating mutation in the gene, 1100delC, was associated with a two-fold increase in breast cancer risk in the CHEK2 Breast Cancer Case-Control Consortium pooling project, which comprised 10860 breast cancer cases and 9065 controls from 10 studies in five countries (The CHEK2 Breast Cancer Case-Control Consortium, 2004). The prevalence of the CHEK $2 * 1100$ delC variant among women with and without breast cancer varies among countries (Meijers-Heijboer et al, 2002; Vahteristo et al, 2002; Osorio et al, 2004; Huzarski et al, 2005; Kilpivaara et al, 2005; Bernstein et al, 2006; Weischer et al, 2007).

*Correspondence: Dr L Mellemkjær; E-mail: lene@cancer.dk

${ }^{14}$ See Appendix.

Received 4 July 2007; revised 19 December 2007; accepted 7 January 2008; published online 5 February 2008
A higher prevalence of the mutation has been found among patients with bilateral breast cancer (Broeks et al, 2004; Kilpivaara et al, 2005) and among patients with a family history of breast cancer (Meijers-Heijboer et al, 2002; Vahteristo et al, 2002; Friedrichsen et al, 2004). Carriers of the CHEK2*1100delC mutation are hypothesised to have an increased sensitivity to exposures such as radiation therapy (RT) and chemotherapy that cause DNA double-strand breaks, as the CHEK2 regulates cellcycle checkpoint response pathways that respond to such damage (Nevanlinna and Bartek, 2006). We investigated the risk for contralateral breast cancer (CBC) associated with the CHEK $2^{\star} 1100$ delC germline mutation among approximately 2100 women with breast cancer who were cases and controls in the multicentre Women's Environment, Cancer and Radiation Epidemiology (WECARE) Study (Bernstein et al, 2004). In addition, we explored the joint effect of being a carrier of mutated CHEK2 and having received RT or chemotherapy for breast cancer. 


\section{MATERIALS AND METHODS}

\section{Study population}

Cases in this study were women with asynchronous $\mathrm{CBC}$ and controls were women with unilateral breast cancer (UBC) obtained from the WECARE Study (Bernstein et al, 2004). The participants were identified through five population-based cancer registries: four in the United States (Surveillance Epidemiology and End Results (SEER) registries in Iowa, Seattle, Los Angeles County and Orange County/San Diego) and one in Denmark (Danish Breast Cancer Cooperative Group (DBCG) registry supplemented by data from the Danish Cancer Registry). Case women were eligible for the study if they were under age 55 years at diagnosis of their first invasive breast cancer and were diagnosed with a second primary breast cancer in the contralateral breast (invasive or in situ) at least 1 year later, while residing in the same reporting area at the time of diagnosis of both cancers with no history of a prior cancer diagnosis or an intervening cancer diagnosis between their first and second primary breast cancers. All first primary breast cancers were invasive without distant metastases and were diagnosed between 1 January 1985 and 31 December 1999. The second primary breast cancer had to have been diagnosed no later than 31 December 2001. All women were alive at the time of contact. Control women had to fulfil the same eligibility criteria as cases except that they had no CBC during the interval between the matched case woman's first and second breast cancers ('at-risk' period) and had no prophylactic mastectomy during the 'at-risk' period. The reference date for case women was the date of diagnosis of their second primary breast cancer, whereas the corresponding reference date for control women was defined as their date of diagnosis of primary breast cancer plus the 'at-risk' period for their matched case. Two UBC controls were individually matched to each $\mathrm{CBC}$ case on year of birth (5-year strata), year of diagnosis (4-year strata), registry region and race, and countermatched on RT (as designated by the cancer registry), that is, each triplet comprised two women who had received RT and one woman who had not. Counter-matching was used to improve the statistical efficiency of the study design (Bernstein et al, 2004).

Characteristics of the first and second breast cancers were abstracted from medical records and cancer registry files. Medical records were retrieved to obtain detailed information on the treatment of the first breast cancer (RT, chemotherapy and hormonal therapy). By the use of methods previously described (Bernstein et al, 2004), the mean individual radiation dose to the contralateral breast was estimated as $1.29 \mathrm{~Gy}$ (range: $0.03-4.68 \mathrm{~Gy}$ ) (estimation carried out for $85 \%$ of those who received RT). Among women treated with chemotherapy, 54\% had received CMF, CF or CM (C, cyclophosphamide; M methotrexate; F, fluorouracil), $23 \%$ had received CAF, CEF, CMAF, CAM, CMEF or AC (A, adriamycin; $\mathrm{E}$, epirubicine) and $23 \%$ had received other or unknown regimens. All the women were interviewed by telephone using a structured questionnaire to obtain information on known breast cancer risk factors. In addition, for the small subset of women for whom medical records did not give information on chemotherapy (7\%) and/or hormonal therapy (10\%), treatment information was obtained at the interview. Blood samples were drawn by study phlebotomists. Study participants were genotyped for mutations in $B R C A 1$ and BRCA2 genes as previously described (Begg et al, 2008). All participants provided written informed consent before enrolment into the WECARE Study, and the research protocol was approved by the respective Institutional Review Boards and the ethical committee system in Denmark.

A
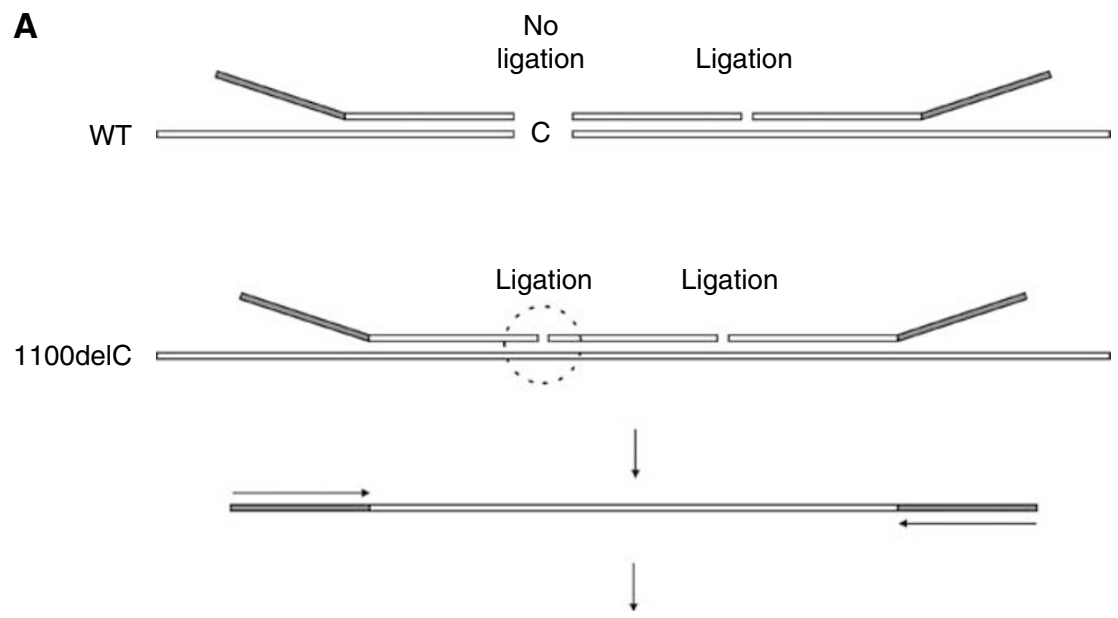

$\underline{\text { PCR product }}$

B

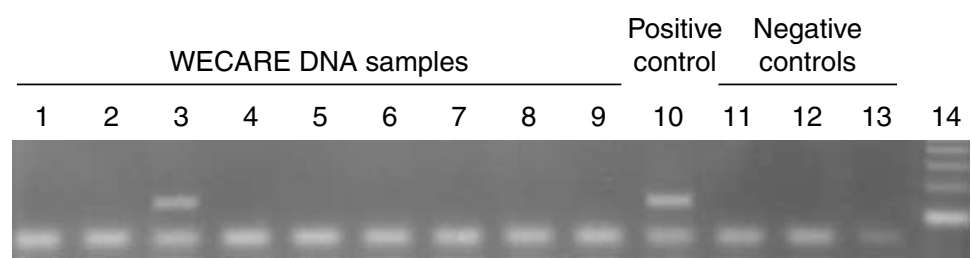

Figure I Detection of CHEK2*I I00delC by oligonucleotide ligation. (A) Schematic of the method. Total genomic DNA is incubated with three oligonucleotides. On the CHEK2*1 I 00de/C sequence, the oligonucleotides hybridise in juxtaposition on the target sequence and can be joined by ligation and subsequently amplified by PCR. On the wild-type CHEK2 sequence, two of the oligonucleotides are separated by one base (C) and cannot be ligated into an amplifiable probe. (B) Analysis of WECARE samples. The controls include DNA samples with (lane I0) and without (lane I I) CHEK2* I I00delC, a ligation control without DNA (lane 12), and a negative PCR control (lane 13). Lane 14, 100 bp ladder. 
Among 998 CBC patients (cases) and 2112 UBC controls who were eligible and approached to participate in the study, 708 (71\%) cases and 1399 (66\%) controls were enrolled. Matching was successfully carried out for 694 triplets (matching criteria were relaxed on region or race/ethnicity for 17 triplets) and 11 casecontrol pairs, whereas three cases had no matched controls. All 708 cases and 1395 of the controls (99.7\%) were genotyped for CHEK $2 * 1100$ delC (four controls excluded).

\section{Genotyping of $\mathrm{CHEK}{ }^{\star} 1100 \mathrm{delC}$}

For detection of $C H E K 2 * 1100 \mathrm{delC}$, we developed an assay based on ligation-dependent amplification (Figure 1). The sequences of the oligonucleotides were $5^{\prime}$-[TATGTAAAACGACGGCCAGT]-TGGCA AGTTCAACATTATTCCCTTTTGTACTGAATTTTAGATTA- ${ }^{\prime}, 5^{\prime}$ TGATTTTGGGCACTCCAAGATTTTGGG- ${ }^{\prime}$ and $5^{\prime}$-AGAGACCTC TCTCATGAGAACCTTATGTGGAACC-[ACCCAATTCGCCCTATAA TA]-3'; the latter two oligonucleotides were $5^{\prime}$-phosphorylated. Approximately $50 \mathrm{ng}$ of genomic DNA in $5 \mu \mathrm{l}$ TE buffer was incubated at $98^{\circ} \mathrm{C}$ for $10 \mathrm{~min}$ and then cooled at $25^{\circ} \mathrm{C}$. MLPA buffer (1.5 $\mu \mathrm{l}$; MRC-Holland, Amsterdam, the Netherlands) and $2 \mathrm{fmol}$ of each oligonucleotide were added, and the samples were then heated at $95^{\circ} \mathrm{C}$ for $1 \mathrm{~min}$ and incubated at $37^{\circ} \mathrm{C}$ for $16 \mathrm{~h}$ in a total volume of $8 \mu \mathrm{l}$. Ligation of the hybridised oligonucleotides was achieved by the addition of $32 \mu \mathrm{l}$ of a ligase mix containing $3 \mu \mathrm{l}$ ligase buffer A (MRC-Holland), $3 \mu \mathrm{l}$ ligase buffer B (MRCHolland), $1 \mathrm{U}$ Taq DNA ligase (New England Biolabs, Beverly, MA, USA) and incubation at $54^{\circ} \mathrm{C}$ for $15 \mathrm{~min}$. Ligation products were amplified with primers $5^{\prime}$-TATGTAAAACGACGGCCAGT-3' and $5^{\prime}$-TATTATAGGGCGAATTGGGT-3'. Hybridisation, ligation and PCR were performed in 96-well plates, which contained two positive controls (DNA with $C H E K 2^{\star} 1100$ delC), two negative controls (DNA without CHEK ${ }^{\star} 1100 \mathrm{delC}$ ) and two ligation controls (without DNA). The PCR products were resolved by agarose gel electrophoresis.

The reliability of the ligation assay was confirmed by re-analysis of 248 DNA samples from WECARE Study participants using denaturing gradient gel electrophoresis (DGGE), as described previously (Bartkova et al, 2004). We found complete concordance between the results obtained with these two methods ( 3 out of 248 samples screened were positive for mutations). The remaining 1855 samples were then analysed with the ligation assay. All positive results were reconfirmed by DGGE analysis or with the ligation assay for samples where long-range amplification was unsuccessful.

\section{Statistical methods}

Rate ratios (RRs) and corresponding 95\% confidence intervals (CIs) were estimated by univariate conditional logistic regression models accounting for the counter-matched design (details described previously; Bernstein et al, 2004). Multivariable models were adjusted for exact age at diagnosis of the first primary breast cancer, age at menarche ( $<13 / \geqslant 13$ years $)$, menopausal status at reference date (premenopausal/age at menopause $<45$ years/age at menopause $\geqslant 45$ years), number of full-term pregnancies $(0,1,2$, $3, \geqslant 4)$, family history of breast cancer among first-degree relatives (yes/no), lobular histology of the first primary (yes/no), stage of

Table I Frequency of CHEK2* I I 00delC carrier status among women with asynchronous CBC and UBC in the WECARE Study according to age at first breast cancer, race, study centre, family history of breast cancer and estrogen receptor status of first breast cancer

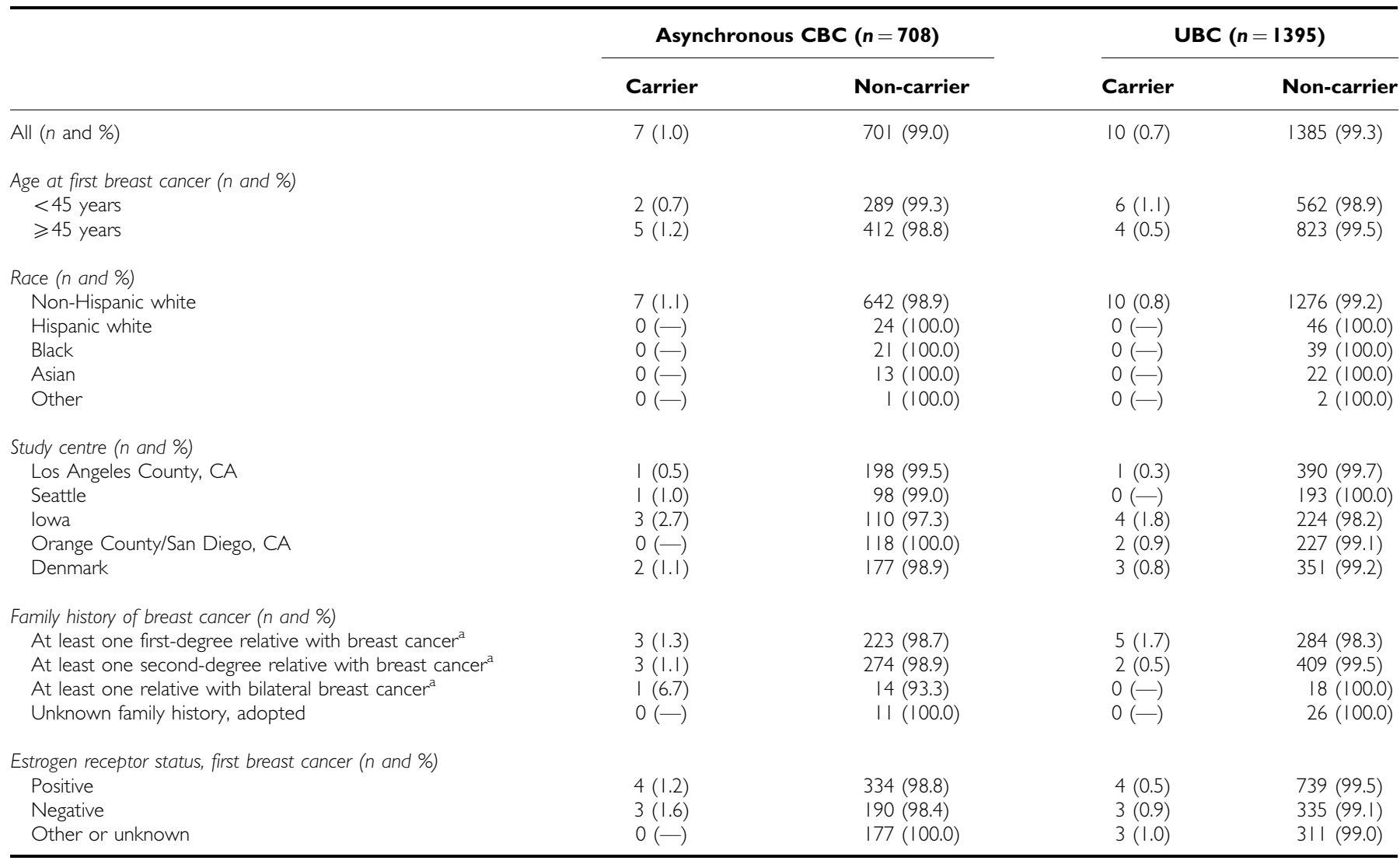

$\mathrm{CBC}=$ contralateral breast cancer; WECARE $=$ Women's Environment, Cancer and Radiation Epidemiology; UBC $=$ unilateral breast cancer. ${ }^{2}$ Women may be in more than one of these categories. 
first breast cancer (local/regional), RT (yes/no), chemotherapy (yes/no) and hormonal therapy (yes/no). As results of the univariate and multivariable models were quite similar, we present RRs from the univariate models. In addition, we present RRs from models adjusted for BRCA1/2 carrier status (deleterious BRCA1/2 mutations yes/no/unknown). The TPHREG procedure in SAS release 9.1 (SAS Institute Inc., Cary, NC, USA) was used for the statistical analyses. Further information about the SAS programming used for counter-matched WECARE data is provided in the appendix of Bernstein et al (2004).

\section{RESULTS}

The mean length of time since first breast cancer diagnosis was 5.0 years (range: $1-15.6$ years) for the total study population. Seven $(1.0 \%)$ carriers of the CHEK $2 * 1100$ delC germline mutation were found among the 708 women with $\mathrm{CBC}$, whereas $10(0.7 \%)$ carriers were found among the 1395 women with UBC. Characteristics of carriers and non-carriers among cases and controls are shown in Table 1.

The association between being carrier of the CHEK2*1100delC mutation and risk of developing CBC was not statistically significant $(\mathrm{RR}=1.7 ; 95 \% \mathrm{CI}=0.6-5.1)$ (Table 2). Compared to women who did not carry the mutation and who did not receive RT for their first breast cancer, carriers who received RT as treatment had an RR of CBC of $2.6(95 \% \mathrm{CI}=0.8-8.4)$. The $\mathrm{RR}$ of CBC among mutation carriers treated with chemotherapy was 1.3 (95\% CI $=0.3-6.2)$ compared with non-carriers who did not receive chemotherapy. We had $90 \%$ statistical power at two-sided $P<0.05$ to exclude a RR of 6.0 for CBC associated with the CHEK $2{ }^{\star} 1100$ delC mutation overall, a RR of 6.9 for the combination of the mutation and RT and a RR of 13.1 for the combination of the mutation and chemotherapy. The RR for the CHEK2*1100delC mutation and $\mathrm{CBC}$ overall was largely unchanged after the adjustment for $B R C A 1 / 2$ carrier status $(\mathrm{RR}=1.8 ; 95 \% \mathrm{CI}=0.6$ 5.4) as were the RRs for the mutation in combination with RT or chemotherapy (Table 2).

Results of analyses restricted to non-Hispanic whites (649 women with $\mathrm{CBC}$ and 1286 women with $\mathrm{UBC}$ ) were similar to those for all study subjects combined.

\section{DISCUSSION}

In this population-based multicentre study, we found a low prevalence of $C H E K 2^{\star} 1100$ delC mutation carriers among 708 women with $\mathrm{CBC}(1.0 \%)$ and 1395 women with UBC $(0.7 \%)$. Several studies have shown higher frequencies (ranging from 1.7 to $14.3 \%$ ) of mutation among women with bilateral breast cancer (Oldenburg et al, 2003; Broeks et al, 2004; Kilpivaara et al, 2005; Chekmariova et al, 2006; Kwiatkowska et al, 2006); however, none of these were population-based. Two of these studies reported that the frequency of mutation was significantly increased among women with bilateral breast cancer compared to women with UBC (Broeks et al, 2004; Kilpivaara et al, 2005). Also, a small but prospective study reported a significant increase in risk for CBC among mutation carriers (de Bock et al, 2004). Three previous studies showing a high carrier prevalence among bilateral breast cancer cases were from the North European countries, the Netherlands (Oldenburg et al, 2003; Broeks et al, 2004) and Finland (Kilpivaara et al, 2005). Although the carrier prevalence among Danish WECARE Study participants is low relative to these prior reports, the prevalence among Danish participants with UBC is similar to that observed in a previous Danish study (Weischer et al, 2007). Differences in frequencies across studies may also be due to differences in study selection criteria, for example, restriction to certain ages at the onset of breast cancer and/or to subjects with family history defined in various ways. Only one of the previous studies on bilateral breast cancer was restricted to non-BRCA1/2 mutation cases (Oldenburg et al, 2003). In contrast to all the previous studies on bilateral breast cancer, which were based on cases from cancer hospitals or genetics clinics, our study is the first that is population-based.

The $C H E K 2{ }^{*} 1100$ delC allele is hypothesised to interact with environmental factors to promote breast tumorigenesis. Ionising radiation is of particular interest because it induces DNA damage, and the protein of the CHEK2 gene is a kinase that plays a role in response to such damage by delaying cell-cycle progression to facilitate DNA repair or even induce cell death (Nevanlinna and Bartek, 2006). The germline mutation 1100delC truncates the CHEK2 protein, thereby abolishing the kinase function (Wu et al, 2001). Epidemiological evidence to substantiate increased radiosensitivity among carriers is, however, sparse (Bernstein et al, 2006; Broeks et al, 2007). Also, although a study conducted in

Table 2 Risk for asynchronous CBC associated with CHEK2*I I O0delC mutation carrier status overall and in combination with RT or chemotherapy for the first breast cancer

\begin{tabular}{|c|c|c|c|c|c|c|}
\hline & \multirow{2}{*}{$\begin{array}{l}\text { No. with asynchronous } \\
\text { CBC }\left(n=705^{\mathrm{a}}\right)\end{array}$} & \multirow[b]{2}{*}{ No. with UBC $(n=1395)$} & \multicolumn{2}{|c|}{ Univariate $^{\mathrm{b}}$} & \multicolumn{2}{|c|}{ Adjusted $^{c}$} \\
\hline & & & $\mathbf{R R}$ & $95 \% \mathrm{Cl}$ & $\mathbf{R R}$ & $95 \% \mathrm{Cl}$ \\
\hline \multicolumn{7}{|l|}{ Mutation } \\
\hline No & 698 & 1385 & 1.00 & - & 1.00 & - \\
\hline Yes & 7 & 10 & 1.7 & $0.6-5.1$ & 1.8 & $0.6-5.4$ \\
\hline \multicolumn{7}{|l|}{ Mutation $\times R T$} \\
\hline No $x$ yes & 339 & 1122 & 1.1 & $0.9-1.3$ & 1.0 & $0.9-1.2$ \\
\hline Yes $\times$ no & 2 & 2 & 0.6 & $0.1-4.2$ & 0.7 & $0.1-5.4$ \\
\hline Yes $\times$ yes & 5 & 8 & 2.6 & $0.8-8.4$ & 2.6 & $0.8-8.7$ \\
\hline \multicolumn{7}{|c|}{ Mutation $\times$ chemotherapy } \\
\hline No × no & 381 & 622 & 1.00 & - & 1.00 & - \\
\hline No $x$ yes & 317 & 763 & 0.6 & $0.5-0.7$ & 0.6 & $0.5-0.7$ \\
\hline
\end{tabular}

$\mathrm{CBC}=$ contralateral breast cancer; $\mathrm{Cl}=$ confidence interval; $\mathrm{RR}=$ rate ratio; $\mathrm{RT}=$ radiation therapy; $\mathrm{UBC}=$ unilateral breast cancer. ${ }^{\text {a Three cases without matched controls }}$ excluded. ${ }^{b}$ RRs adjusted for counter-matching sampling. ${ }^{c}$ RRs adjusted for counter-matching sampling and BRCA//2 carrier status. 
Belgium suggested that breast cancer patients with a $C H E K 2 * 1100$ delC mutation are, in general, not characterised by a distinct enhanced chromosomal radiosensitivity, this conclusion was based on only four breast cancer cases with the mutation who were compared with healthy controls without the mutation (Baeyens et al, 2005). Our result, although not statistically significant, suggests that mutation carriers may have increased radiosensitivity.

The WECARE Study was designed to investigate interactions between genes and exposures that cause DNA double-strand breaks in a study population enriched with hereditary breast cancer cases, owing to the restriction to early-onset breast cancer, and a population heavily exposed to ionising radiation and chemotherapeutic drugs. Detailed information on RT and chemotherapy was obtained by a thorough review of medical records. As DNA samples from WECARE Study participants have also been screened for mutations in $B R C A 1$ and $B R C A 2$ genes, we were able to adjust the analyses for $B R C A$ carrier status. Patients included in the study survived varying lengths of time from reference date to interview; however, cases and controls within each triplet survived approximately the same length of time. The prevalence of the mutation may have been affected if carriers of the $C H E K 2^{\star} 1100$ delC mutation had a worse survival than non-carriers. Unfortunately, we could not address this question, as we had no information on carrier status among the non-survivors who were not included in the study. Previous studies have shown a worse recurrence-free survival (Schmidt et al, 2007) and distant metastases-free survival (de Bock et al, 2004) among carriers compared to non-carriers, but overall survival did not differ by carrier status (de Bock et al, 2004).

Notably, we found a low carrier frequency for the CHEK2*1100delC mutation in this large population-based sample of early-onset cases of $\mathrm{CBC}$ and UBC. The small number of carriers reduced our ability to study the effects of the mutation on the development of $\mathrm{CBC}$; and accordingly, we could not exclude the possibility that the CHEK $2 * 1100$ delC mutation is associated with modest increases in risk. In contrast, the rarity of the CHEK $2{ }^{\star} 1100$ delC mutation indicates that it plays a rather limited role in the aetiology of $\mathrm{CBC}$ in the population.

\section{ACKNOWLEDGEMENTS}

This work was supported by a grant from the Danish Medical Research Council (Grant no. 22-03-0303) and from the National Institutes of Health (Grant no. U01 CA083178, R01 CA097397 and R01 CA114236). The collection of cancer incidence data for the two California data centres was supported by the California Department of Health Services as part of the state-wide cancer reporting program mandated by California Health and Safety Code Section 103885; the National Cancer Institute's Surveillance, Epidemiology and End Results Program under contract N01-PC-35139 awarded to the University of Southern California and contract N02-PC15105 awarded to the Public Health Institute; and the Centers for Disease Control and Prevention's National Program of Cancer Registries, under agreement no. U55/CCR921930-02 awarded to the Public Health Institute. The ideas and opinions expressed herein are those of the authors, and no endorsement by the State of California, Department of Health Services is intended or should be inferred. Further the contents do not necessarily represent the official views of the US Government. Case ascertainment was additionally supported by the NCI SEER Program under contract N01-PC-35142 in Seattle and N01-PC35143 in Iowa. We thank Vibeke Ahrenkiel, Institute of Cancer Biology, Danish Cancer Society for expert technical assistance.

\section{REFERENCES}

Baeyens A, Claes K, Willems P, De Ruyck K, Thierens H, Vral A (2005) Chromosomal radiosensitivity of breast cancer with a CHEK2 mutation. Cancer Genet Cytogenet 163: $106-112$

Bartkova J, Guldberg P, Gronbaek K, Koed K, Primdahl H, Moller K, Lukas J, Orntoft TF, Bartek J (2004) Aberrations of the Chk2 tumour suppressor in advanced urinary bladder cancer. Oncogene 23: 8545-8551

Begg CB, Haile RW, Borg A, Malone KE, Concannon P, Thomas DC, Langholz B, Bernstein L, Olsen JH, Lynch CF, Anton-Culver H, Capanu M, Liang X, Hummer AJ, Sima C, Bernstein JL (2008) Variation of breast cancer risk among $B R C A 1 / 2$ carriers: an investigation by the WECARE study group. JAMA 299: 194-201

Bernstein JL, Langholz B, Haile RW, Bernstein L, Thomas DC, Stovall M, Malone KE, Lynch CF, Olsen JH, Anton-Culver H, Shore RE, Boice Jr JD, Berkowitz GS, Gatti RA, Teitelbaum SL, Smith SA, Rosenstein BS, Borresen-Dale AL, Concannon P, Thompson WD (2004) Study design: evaluating gene-environment interactions in the etiology of breast cancer - the WECARE study. Breast Cancer Res 6: R199-R214

Bernstein JL, Teraoka SN, John EM, Andrulis IL, Knight JA, Lapinski R, Olson ER, Wolitzer AL, Seminara D, Whittemore AS, Concannon P (2006) The $C H E K 2^{\star} 1100$ delC allelic variant and risk of breast cancer: screening results from the breast cancer family registry. Cancer Epidemiol Biomarkers Prev 15: $348-352$

Broeks A, Braaf LM, Huseinovic A, Nooijen A, Urbanus J, Hogervorst FBL, Schmidt MK, Klijn JGM, Russell NS, van Leeuwen FE, van't Veer LJ (2007) Identification of women with an increased risk of developing radiation-induced breast cancer: a case only study. Breast Cancer Res 9: R26

Broeks A, de Witte L, Nooijen A, Huseinovic A, Klijn JG, Van Leeuwen FE, Russell NS, van't Veer LJ (2004) Excess risk for contralateral breast cancer in CHEK $2^{\star} 1100$ delC germline mutation carriers. Breast Cancer Res Treat 83: $91-93$

CHEK2 Breast Cancer Case-Control Consortium (2004) CHEK2*1100delC and susceptibility to breast cancer: a collaborative analysis involving
10,860 breast cancer cases and 9,065 controls from 10 studies. Am J Hum Genet 74: $1175-1182$

Chekmariova EV, Sokolenko AP, Buslov KG, Iyevleva AG, Ulibina YM, Rozanov ME, Mitiushkina NV, Togo AV, Matsko DE, Voskresenskiy DA, Chagunava OL, Devilee P, Cornelisse C, Semiglazov VF, Imyanitov EN (2006) CHEK2 1100delC mutation is frequent among Russian breast cancer patients. Breast Cancer Res Treat 100: 99-102

de Bock GH, Schutte M, Krol-Warmerdam EM, Seynaeve C, Blom J, Brekelmans CT, Meijers-Heijboer H, van Asperen CJ, Cornelisse CJ, Devilee P, Tollenaar RA, Klijn JG (2004) Tumour characteristics and prognosis of breast cancer patients carrying the germline CHEK2*1100delC variant. J Med Genet 41: $731-735$

Friedrichsen DM, Malone KE, Doody DR, Daling JR, Ostrander EA (2004) Frequency of CHEK2 mutations in a population based, case-control study of breast cancer in young women. Breast Cancer Res 6: R629-R635

Huzarski T, Cybulski C, Domagala W, Gronwald J, Byrski T, Szwiec M, Woyke S, Narod SA, Lubinski J (2005) Pathology of breast cancer in women with constitutional CHEK2 mutations. Breast Cancer Res Treat 90: $187-189$

Kilpivaara O, Bartkova J, Eerola H, Syrjakoski K, Vahteristo P, Lukas J, Blomqvist C, Holli K, Heikkila P, Sauter G, Kallioniemi OP, Bartek J, Nevanlinna H (2005) Correlation of CHEK2 protein expression and c.1100delC mutation status with tumor characteristics among unselected breast cancer patients. Int J Cancer 113: 575-580

Kwiatkowska E, Skasko E, Niwinska A, Wojciechowska-Lacka A, Rachtan J, Molong L, Nowakowska D, Konopka B, Janiec-Jankowska A, Paszko Z, Steffen J (2006) Low frequency of the CHEK2*1100delC mutation among breast cancer probands from three regions of Poland. Neoplasma 53: $305-308$

Meijers-Heijboer H, van den Ouweland A, Klijn J, Wasielewski M, de Snoo A, Oldenburg R, Hollestelle A, Houben M, Crepin E, van VeghelPlandsoen M, Elstrodt F, van Duijn C, Bartels C, Meijers C, Schutte M, McGuffog L, Thompson D, Easton D, Sodha N, Seal S, Barfoot R, 
Mangion J, Chang-Claude J, Eccles D, Eeles R, Evans DG, Houlston R, Murday V, Narod S, Peretz T, Peto J, Phelan C, Zhang HX, Szabo C, Devilee P, Goldgar D, Futreal PA, Nathanson KL, Weber B, Rahman N, Stratton MR (2002) Low-penetrance susceptibility to breast cancer due to $C H E K 2^{*} 1100$ delC in noncarriers of $B R C A 1$ or BRCA2 mutations. Nat Genet 31: 55-59

Nevanlinna H, Bartek J (2006) The CHEK2 gene and inherited breast cancer susceptibility. Oncogene 25: 5912-5919

Oldenburg RA, Kroeze-Jansema K, Kraan J, Morreau H, Klijn JG, Hoogerbrugge N, Ligtenberg MJ, van Asperen CJ, Vasen HF, Meijers C, Meijers-Heijboer H, de Bock TH, Cornelisse CJ, Devilee P (2003) The CHEK $2{ }^{*} 1100$ delC variant acts as a breast cancer risk modifier in nonBRCA1/BRCA2 multiple-case families. Cancer Res 63: 8153-8157

Osorio A, Rodriguez-Lopez R, Diez O, de la Hoya M, Martinez JI, Vega A, Esteban-Cardenosa E, Alonso C, Caldes T, Benitez J (2004) The breast

\section{Appendix}

\section{CORPORATE AUTHORSHIP LIST}

WECARE Study Collaborative Group for WECARE: CHEK2*1100delC

PI: Jørgen H Olsen, MD, DMSc; Co-investigators named on grant: Jonine L Bernstein, PhD, Anne-Lise Børresen-Dale, PhD, Ake Borg, PhD, Lisbeth Bertelsen, MD, Lene Mellemkjær, PhD, MSc, Per Guldberg, PhD.

Coordinating Center: Memorial Sloan-Kettering Cancer Center (New York, NY, USA) Jonine L Bernstein, PhD (WECARE Study PI), Xiaolin Liang, MD, MS (Informatics Specialist), Abigail Wolitzer, MSPH (Project Director); National Cancer Institute (Bethesda, MD, USA) Daniela Seminara, PhD, MPH (Program Officer).

Laboratories $^{\star}$ : Danish Cancer Society (Copenhagen, Denmark) Per Guldberg, PhD; University of Southern California (Los Angeles, CA, USA) Robert W Haile, Dr PH (PI), Anh T Diep (Laboratory Director), Nianmin Zhou, MD (Laboratory Manager), Yong Liu, MD (Director of Blood Processing), Evgenia TerKarapetova (Supervisor of Biospecimen Processing), Andre Hernandez; Memorial Sloan-Kettering Cancer Center (New York, NY, USA) Irene Orlow, PhD (Laboratory Director, Biorepository). cancer low-penetrance allele 1100delC in the CHEK2 gene is not present in Spanish familial breast cancer population. Int J Cancer 108: 54-56 Schmidt MK, Tollenaar RA, de Kemp SR, Broeks A, Cornelisse CJ, Smit VT, Peterse JL, van Leeuwen FE, Van't Veer LJ (2007) Breast cancer survival and tumor characteristics in premenopausal women carrying the CHEK2*1100delC germline mutation. J Clin Oncol 25: 64-69

Vahteristo P, Bartkova J, Eerola H, Syrjakoski K, Ojala S, Kilpivaara O, Tamminen A, Kononen J, Aittomaki K, Heikkila P, Holli K, Blomqvist C, Bartek J, Kallioniemi OP, Nevanlinna H (2002) A CHEK2 genetic variant contributing to a substantial fraction of familial breast cancer. Am J Hum Genet 71: 432-438

Weischer M, Bojesen SE, Tybjaerg-Hansen A, Axelsson CK, Nordestgaard BG (2007) Increased risk of breast cancer associated with CHEK2*1100delC. J Clin Oncol 25: 57-63

Wu X, Webster SR, Chen J (2001) Characterization of tumor-associated Chk2 mutations. J Biol Chem 276: 2971-2974

Epidemiology/Data Collection Centers*: Danish Cancer Society (Copenhagen, Denmark) Jørgen H Olsen, MD, DMSc (PI), Lene Mellemkjær, PhD, MSc (Project Manager), Per Guldberg, PhD, Lisbeth Bertelsen, MD; University of Southern California (Los Angeles, CA, USA) Leslie Bernstein, PhD (PI), Laura DonnellyAllen (Project Manager); University of Iowa (Iowa City, IA, USA) Charles F Lynch, MD, PhD (PI), Jeanne DeWall, MA (Project Manager); Fred Hutchinson Cancer Research Center (Seattle, WA, USA) Kathleen E Malone, PhD (PI), Noemi Epstein (Project Manager); University of California at Irvine (Irvine, CA, USA) Hoda Anton-Culver, PhD (PI), Joan Largent, PhD, MPH (Project Manager).

Radiation Measurement: University of Texas, MD Anderson Cancer Center (Houston, TX, USA) Marilyn Stovall, PhD (PI), Susan Smith, MPH (Quality Assurance Dosimetry Supervisor); New York University (New York, NY, USA) Roy E Shore, PhD, Dr PH (Epidemiologist); International Epidemiology Institute (Rockville, MD, USA) and Vanderbilt University (Nashville, TN, USA) John D Boice Jr, ScD (Consultant).

Biostatistics Core: University of Southern California (Los Angeles, CA, USA) Bryan M Langholz, PhD, Duncan C Thomas, $\mathrm{PhD}$; Memorial Sloan-Kettering Cancer Center (New York, NY, USA) Colin Begg, PhD, Marinela Capanu, PhD; University of Southern Maine (Portland, ME, USA) W Douglas Thompson, PhD (PI). 